\title{
Problems of analysis of axially loaded steel behavior under laser welded panel
}

\author{
Problemy związane z analizą zachowania się stalowego panelu \\ spawanego laserowo pod obciążeniem ściskającym
}

\begin{abstract}
Application of new structural idea requires obtaining data for modelling processes. Such a new idea is a steel laser welded sandwich panel. The paper presents selected problems concerning to modelling processes of such structure. Theoretical proposals for stiffness coefficients are presented and results of systematic buckling tests of natural scale models are discussed.
\end{abstract}

KEYWORDS: laser welding, new structural material, light structures

Among new construction materials, there are steel sandwich panels, welded with laser. They can be defined as three-layer structures consisting of two thin layers of outer sheathing made of high-strength material (they determine strength properties), between which there is a thicker layer - usually with different strength properties than the extreme layers. It maintains the correct geometry of the extreme layers, and also shapes the insulation of the structure, acoustic and thermal resistance as well as vibrational characteristics [1].

\section{Specificity of material properties of the laser weld}

Laser welds of steel sandwich panels are characterized by a very large hardness gradient - both in the direction parallel and perpendicular to the plane of the panel (fig. 1).
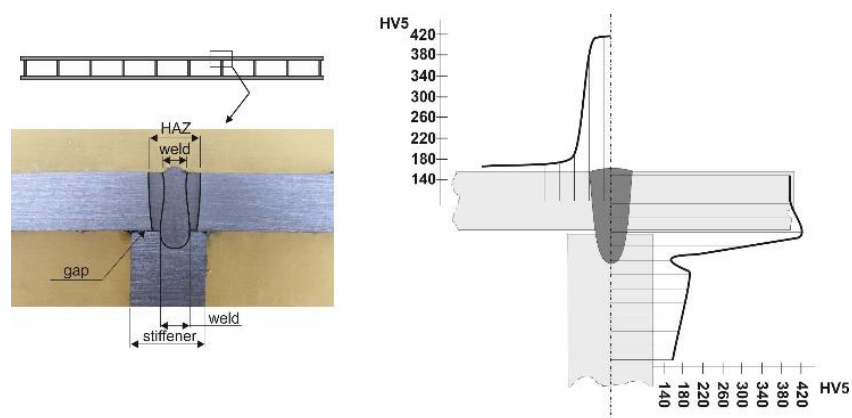

Fig. 1. Material zones (on the left) and changes in the hardness of the laser weld (on the right) [1, 7]

\footnotetext{
* Dr hab. inż. Janusz Kozak, prof. ndzw (kozak@pg.edu.pl) - Politechnika Gdańska, Wydz. Oceanotechniki i Okrętownictwa
}

Five characteristic zones can be distinguished in this connection:

- native material,

- heat affected zone,

- joint,

- an intermediate zone between the native material and the heat affected zone,

- transition zone between the heat affected zone and the weld.

Results of cyclic fatigue tests of steel sandwich panels are shown in fig. 2.

During the tests, changes in deformations in the joint zone were recorded and hysteresis curves were made on this basis, allowing to determine the values of the strengthening coefficient and exponent in the RambergOsgood equation:

$$
\epsilon=\frac{\sigma}{E}+K \cdot\left(\frac{\sigma}{E}\right)^{n}
$$

where: $\varepsilon$ - strain, $\sigma$ - stress, $E$ - Young's modulus, $K$ strengthening factor, $n$ - exponent of the strengthening.
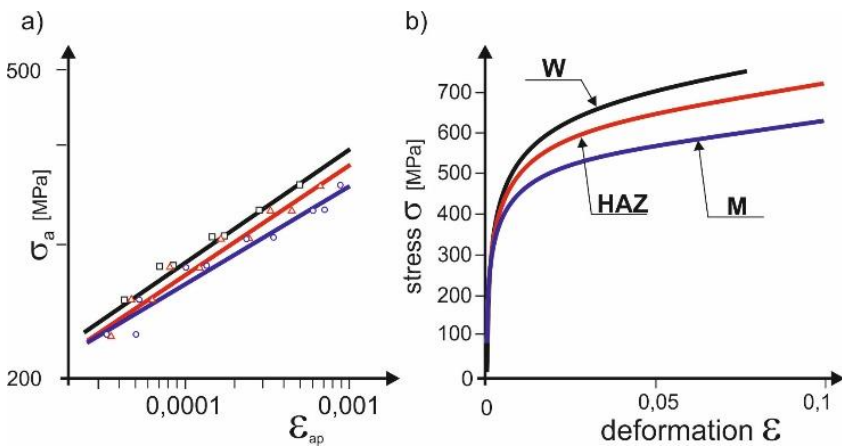

Fig. 2. Plots of cyclic deformation for laser weld zones: a) in the system amplitude of plastic strain - stress amplitude $\left.\left(\varepsilon_{a p}-\sigma_{a}\right), b\right)$ dependence described by Ramberg-Osgood [2]; explanations: $W$ - weld, $H A Z$ - heat affected zone, $M$ - native material

When comparing $K$ and $n$ constants for laser welds joining standard thickness steel sheets $(12 \mathrm{~mm})$ and laser welds of steel sandwich panels (see table) it can be concluded that exponents $n$ have similar values, while the strengthening coefficient $K$ is much larger in case of joints of sandwich panels. Strength coefficients for the material of the native laser joints connecting the $12 \mathrm{~mm}$ sheets and the sheet metal of the $2.5 \mathrm{~mm}$ sandwich panels were very similar. The coefficient $K$ of the laser weld material zone 
in the case of $12 \mathrm{~mm}$ sheets increased by $4 \%$, and in the case of sandwich panels - by $30 \%$.

TABLE. Cyclic properties of material zones of the laser weld of sandwich panels [2]

\begin{tabular}{|c|c|c|}
\hline \multirow{2}{*}{ Connection zone } & $\mathrm{n}$ & $\mathrm{K}$ \\
\cline { 2 - 3 } & - & $\mathrm{MPa}$ \\
\hline Weld S & 0.1493 & 1108 \\
\hline Heat affected zone & 0.1426 & 1008 \\
\hline Native material & 0.1262 & 842 \\
\hline
\end{tabular}

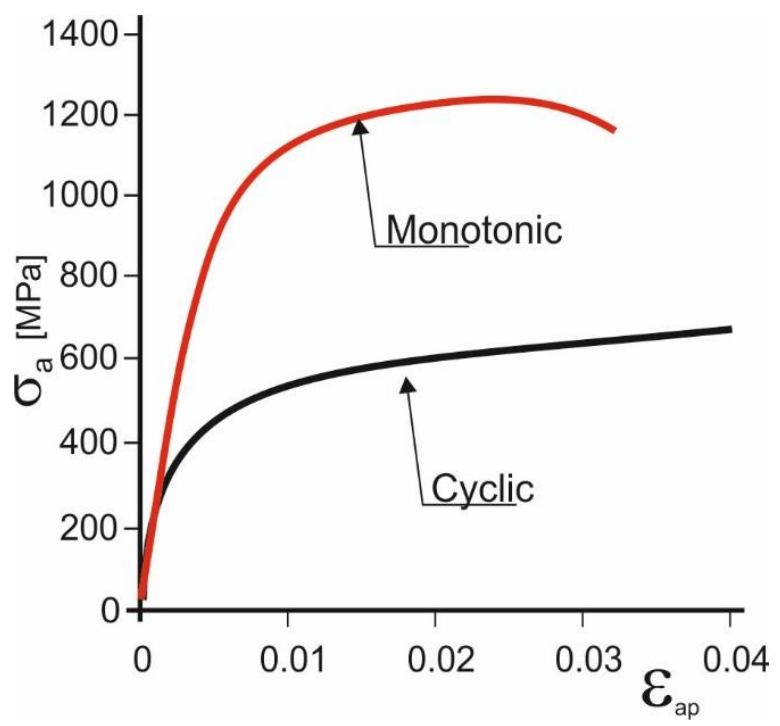

Fig. 3. Graph of monotonic stretching and cyclic deformation for laser connection (weld zone) [2]

Similar differentiations are shown by the results of the tensile test and cyclic deformation (fig. 3).

It can be expected that the weld features discussed in these laser welded joints (regarding both geometry and deformation characteristics) affect the rigidity and strength properties of the joint. The methodology of modeling the properties of laser welds of steel sandwich panels should take into account the material and geometric diversity of analyzed joints. In comparison with classical welds, laser welds show much larger differences in material properties between the individual connection zones.

\section{Modeling of deformation of sandwich panels loaded along stiffeners}

Kolsters and Zenkert [3] presented theoretical model of buckling of the elastic panel with the filler, loaded along the stiffeners. During the considerations, they accepted different models proposed by other authors, and they chose the model shown in fig. 4 for the assumptions. In the assumptions, the sheathing plate between two stiffeners was treated as a rectangular shell on a continuous elastic support supported on unencumbered edges.

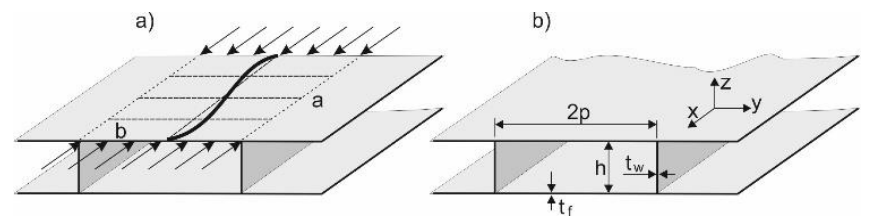

Fig. 4. Buckling in plane coating (a) and characteristic dimensions (b) of a laser welded panel

For such a load, the proposed approaches differ in the way of modeling the elastic support, which in turn determines the method of modeling the mechanism of distributing lateral stresses in the filler. By following approaches of different authors, it can be distinguished: Winkler's model (without transferring cutting stresses), a two-parametric model of Pasternak's support (linear decay of cutting stresses) and a flexible model with exponential distribution.

Therefore, in the modeling process, it is important to separately model the share of tensile-compression and shearing stresses and to distinguish between the symmetrical and anti-symmetrical undulation of the coat (fig. 5).

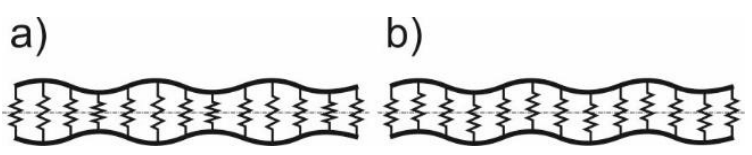

Fig. 5. Symmetrical (a) and anti-symmetrical (b) buckling (Winkler model)

The approach according to the one suggested by Winkler results in the simplest support model [4], in which the filler is modeled as an array of evenly distributed springs, causing a symmetrical buckling in relation to the central plane (fig. 5). In the anti-symmetrical case, springs remain unloaded even after buckling. Because the tangential deformation of the filler is not taken into account, the Winkler model is unsuitable for fillers with a high modulus of elasticity and undulations of a low wavelength plating.

For I-core panels, the expression for rigidity coefficients was developed by Kolsters et al. [5]. Kujala and Klanac also dealt with this subject [6]. For selected panel geometries without filler, analytical expressions can be derived into component stiffness coefficients.

In the case of the panel with geometry of type l-core defined in fig. $4 \mathrm{~b}$, and assuming that $E_{c}, E_{f}, E_{w}$ are the modulus of elasticity of the filler material, plating and stiffeners, and $v_{c}, v_{f}, v_{w}$ - Poisson numbers of the filler material, plating and stiffeners, bending rigidity in the direction parallel to stiffeners is expressed with the formula $[4,5]$ :

$$
D_{x}=\frac{E_{f} \cdot h^{2} \cdot t_{f}}{2}+\frac{E_{w} \cdot I_{w x}}{2 \cdot p}
$$

where:

$$
I_{w x}=\frac{t_{w} \cdot\left(h-t_{f}\right)^{3}}{12}
$$


Rigidity for bending in the transverse direction to stiffeners is expressed as:

$$
D_{y}=\frac{E_{f} \cdot h^{2} \cdot t_{f}}{2}
$$

while torsional rigidity:

$$
D_{x y}=G_{f} \cdot h^{2} \cdot t_{f}
$$

where:

$$
G_{f}=\frac{E_{f}}{2 \cdot\left(1+v_{f}\right)}
$$

Shear rigidity in the direction parallel to the stiffeners is described by the dependence:

$$
D_{q x}=\frac{G_{w} \cdot h \cdot t_{w}}{2 \cdot p}
$$

where :

$$
G_{w}=\frac{E_{w}}{2 \cdot\left(1+v_{w}\right)}
$$

Shear rigidity in transverse direction to stiffeners:

$$
D_{q y}=\frac{1}{\frac{\left(p-\frac{t_{w}}{2}\right)^{3}}{6 \cdot E_{f} \cdot I_{f} \cdot p}+\frac{p \cdot h}{12 \cdot E_{w} \cdot I_{w}}\left(\left(\frac{t_{f}}{h}\right)^{3}-3\left(\frac{t_{f}}{h}\right)+2\right)}
$$

where:

$$
\begin{gathered}
I_{\mathrm{f}}=\frac{t_{\mathrm{f}}^{3}}{12} \\
I_{w}=\frac{t_{w}^{3}}{12}
\end{gathered}
$$

Rigidity coefficients for panels with I-core geometry with foam filler were provided by Kolsters and Zenkert [3]. For this type of panels, the bending rigidity indices $D_{x}, D_{y}$ and $D_{x y}$ are practically the same as for empty panels (as shown earlier).

Shear rigidity in the direction parallel to stiffeners is defined as follows:

$$
D_{q x}=\frac{h}{2 \cdot p}\left(G_{w} \cdot t_{w}+G_{c} \cdot\left(2 \cdot p-t_{w}\right)\right)
$$

where :

$$
G_{c}=\frac{E_{C}}{2 \cdot\left(1+v_{c}\right)}
$$

Shear rigidity in transverse direction to stiffeners:

$$
D_{q y}=\frac{1}{\frac{\left(p-\frac{t_{w}}{2}\right)^{3}}{6 \cdot E_{f} \cdot I_{f} \cdot p}+\frac{p \cdot h}{12 \cdot E_{w} \cdot I_{w}}\left(\left(\frac{t_{f}}{h}\right)^{3}-3\left(\frac{t_{f}}{h}\right)+2\right)+\frac{1}{G_{c} \cdot\left(h-t_{f}\right)}}
$$

\section{Laboratory tests on the load-bearing capacity of sandwich panels loaded along stiffeners}

The purpose of tests on the strength of sandwich models for the compressive load acting in the model plane and applied to the shorter edges was to find the relationship between the model geometry and the filler parameters and the structure destruction mechanism. The research was carried out on a group of models with different combinations of geometry and height of stiffeners, thicknesses of the plating panels and density of the filling material (fig. 6). The models used a fixed spacing of stiffeners equal to $80 \mathrm{~mm}$ and a constant thickness of stiffeners $-4 \mathrm{~mm}$. As variable parameters were assumed:

- coating board thickness $t_{f}-1 \mathrm{~mm}$ and $3 \mathrm{~mm}$,

- height of stiffeners $h-20 \mathrm{~mm}$ and $60 \mathrm{~mm}$,

- filling: empty $(E)$ and high density filler $(H)$. a)

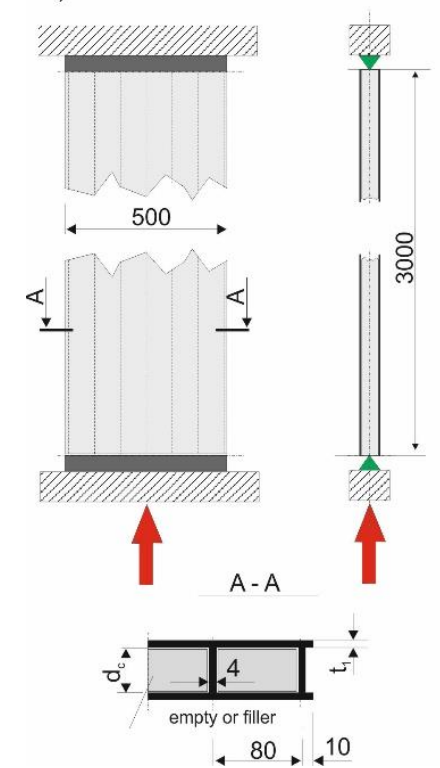

b)

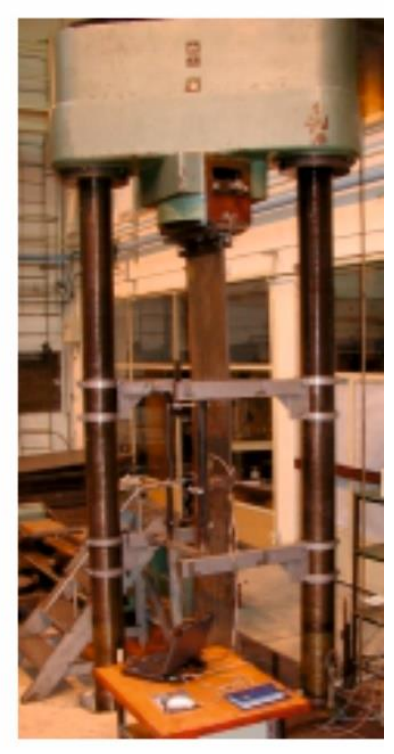

Fig. 6. Geometry of the compression test models [7]

\section{Conclusions}

It has been shown that correct modeling of the properties of a laser welded joint requires careful consideration of the geometry and material characteristics of each of its zones. On the example of destruction of the real structure (fig. 7), it can be seen that depending on the geometry of the model, destruction takes place according to two separate mechanisms - buckling or global bending. 


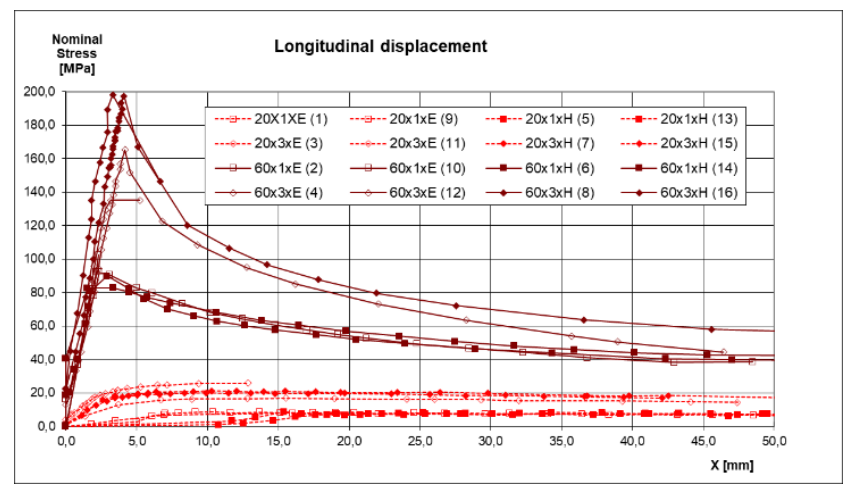

Fig. 7. Longitudinal deformation of the model as a function of compressive stress [7]. For example, a record of $20 \times 1 \times E$ means: height of stiffener $20 \mathrm{~mm}$, coating thickness $1 \mathrm{~mm}$, E - lack of filling

\section{REFERENCES}

1. Boroński D., Kozak J., Research on deformations of laserwelded joint of a steel sandwich structure model, Polish Maritime Research nr 2(40) vol. 11, 2004.

2. D. Boroński i J. Szala, Tests of local strains in steel laserwelded sandwich structure, Gdańsk: Polish Maritime Research, Special issue 2006/S1, ISSN 1233-2585, 2006.

3. Kolsters, H., Zenkert, D. (2006) Buckling of laser-welded sandwich panels. Part 1: Elastic buckling parallel to the webs. Journal of Engineering for the Maritime Environment (Part M), 220(2): pages 69-79.

4. Zenkert D., An Introduction to Sandwich Construction, Engineering Materials Advisory Services.

5. P. Kujala, Previous Development and Applications of Laser Welded all Metal Sandwich Panels 2, Helsinki: Internal report of Sandwich projekt, Helsinki University of technology, Ship laboratory, 2000.

6. P. Kujala i J. Tuhkuri, All steel corrugated core sandwich panels for ship structures, Southampton: Paper read at Sandwich Construction Conference, 1995.

7. Kozak J., Problemy oceny wybranych własności wytrzymałościowych stalowych, dwupowłokowych struktur okrętowych, Gdańsk: Wydawnictwo Politechniki Gdańskiej, ISBN 837348-136-2, 2005. 